\title{
Synthesis of Dumbbell-Shaped Au-Ag Core-Shell Nanorods by Seed-Mediated Growth under Alkaline Conditions
}

\author{
Chih-Ching Huang, Zusing Yang, and Huan-Tsung Chang* \\ Department of Chemistry, National Taiwan University, Taipe, Taiwan \\ Received May 15, 2004
}

\begin{abstract}
We report a simple synthesis of $\mathrm{Au}-\mathrm{Ag}$ core-shell nanorods (NRs) under alkaline conditions (pH 8.010.0) from silver and ascorbate ions using gold nanorods (GNRs) as the seeds. The silver ions that are reduced by the ascorbate ions become deposited on the surfaces of the GNRs to form differently dumbbellshaped $\mathrm{Au}-\mathrm{Ag}$ core-shell NRs and nanoparticles, depending on the $\mathrm{pH}$ and the concentration of silver ions. The longitudinal plasmon absorbance bands of the Au-Ag core-shell NRs are stronger and appear at shorter wavel engths than those for the original GNRs. Weconfirmed theformation of Au-Ag core-shell NRs by both energy-dispersive X-ray spectrometry and inductively coupled plasma mass spectrometry measurements, which indicate that the ${ }^{109} \mathrm{Ag} / 197 \mathrm{Au}$ ratios are $0.046,0.085$, and 0.097 at $\mathrm{pH} 8.0,9.0$, and 10.0, respectively. The transmission el ectron microscopy measurements show that the Au-Ag core-shell NRs are monodispersed (>90\%).
\end{abstract}

Nanoparticles (NPS) exhibit significantly different properties relative to those of their corresponding bulk materials and, as such, are of interest for applications in catalysis, electronics, and optics. ${ }^{1-9}$ Gold nanoparticles (GNPs) can be used as sensors because of the size and shape dependence of their optical properties and the ease by which their surfaces can be modified using biological molecules, such as proteins and DNA, mainly through Au-S bonding. ${ }^{6}$ Spherical GNPs can be synthesized readily by the chemical reduction of gold salts; ${ }^{10,11}$ anisotropic GNPs, such as gold nanorods (GNRs), can be prepared by a variety of methods, such as templating, ${ }^{12}$ photochemistry, ${ }^{13}$ seeding, ${ }^{14}$ and el ectrochemistry. ${ }^{15}$ The properties of the surfactants ${ }^{13-15,16}$ and organic solvents, ${ }^{14,15}$ as well as the concentration of the seeds, ${ }^{17}$ are

* To whom correspondence may be addressed. Tel./fax: 011886-2-23621963. E-mail: changht@ntu.edu.tw

(1) Eychmuller, A. J . Phys. Chem. B 2000, 104, 6514-6528.

(2) El-Sayed, M. A. Acc. Chem. Res. 2001, 34, 257-264.

(3) Gambardella, P.; Rusponi, S.; Veronese, M.; Dhesi, S. S.; Grazioli, C.; Dallmeyer, A.; Cabria, I.; Zeller, R.; Dederichs, P. H.; Kern, K.; Carbon, C.; Brune, H. Science 2003, 300, 1130-1133.

(4) Bell, A. T. Science 2003, 299, 1688-1691.

(5) Cui, Y.; Wei, Q.; Park, H.; Lieber, C. M. Science 2001, 293, 12891292.

(6) Storhoff, J. I.: Lazarids, A. A.; Mucic, R. C.; Mirkin, C. A.; Letsinger, R. L.; Schatz, G. C.J . Am. Chem. Soc. 2000, 122, 4640-4650. (7) Mulvaney, P. Langmuir 1996, 12, 788-800.

(8) Kelly, K. L.; Coronado, E.; Zhao, L. L.; Schatz, G. C. J . Phys. Chem. B 2003, 107, 668-677.

(9) Link, S.; Mohamed, M. B.; El-Sayed, M. A. J . Phys. Chem. B 1999, 103, 3073-3077.

(10) Turkevich, J .; Stevenson, P. C.; Hillier, J . Discuss. Faraday Soc. 1951, 11, 55-75.

(11) Frens, G. Nat. Phys. Sci. 1973, 241, 20-22.

(12) (a) van der Zande, B. M. I.; Böhmer, M. R.; Fokkink, L. G. J .; Schönenberger, C.J . Phys. Chem. B 1997, 101, 852-854. (b) NicewarnerPeña, S. R.; Freeman, R. G.; Reiss, B. D.; He, L.; Peña, D. J .; Walton, I. D.; Cromer, R.; Keating, C. D.; Natan, M. J. Science 2001, 294, 137141.

(13) (a) Esumi, K.; Matsuhisa, K.; Torigoe, K. Langmuir 1995, 11 , 3285-3287. (b) Kim, F.; Song, J. H.; Yang, P. J . Am. Chem. Soc. 2002, 124, 14316-14317.

(14) (a) Murphy, C. J .; J ana, N. R. Adv. Mater. 2002, 14, 80-82. (b) Busbee, B. D.; Obare, S. O.; Murphy C. J . Adv. Mater. 2003, 15, 414416. (c) Taub, N.; Krichevski, O.; Markovich, G.J . Phys. Chem. B 2003, 107, 11579-11582. (d) Nikoobakht, B.; El-Sayed, M. A. Chem. Mater. 2003, 15, 1957-1962.

(15) (a) Yu, Y.-Y.; Chang, S.-S.; Lee, C.-L.; Wang, C. R. C. J . Phys. Chem. B 1997, 101, 6661-6664. (b) Chang, S.-S.; Shih, C.-W.; Chen, C.-D.; Lai, W.-C.; Wang, C. R. C. Langmuir 1999, 15, 701-709. important parameters for controlling the aspect ratios (length:width) of the GNRs. In addition, the concentration of silver ions is also critical to the control of the aspect ratio of GNRs prepared by photochemical means. ${ }^{13 b, 14 d}$

Core-shell bimetallic nanoparticles exhibiting characteristic electronic, optical, and catalytic properties, which are different from those of their individual constituent metals, are of considerable interest in basic and applied science. ${ }^{18,19}$ In this paper, we describe an easy approach to the synthesis of differently shaped Au-Ag core-shell nanorods (NRs) from silver ions and ascorbic acid, under alkal ine conditions, using GN Rs (aspect ratio $=3.92$ ) as seeds. At low pH, ascorbic acid (the values of $\mathrm{pK}_{\mathrm{a} 1}$ and $\mathrm{pK}_{\mathrm{a} 2}$ are 4.10 and 11.79, respectively), which is incapable of reducing silver ions, is the major species; the fraction of monoanionic ascorbate species, which are capable of reducing silver ions, increases as the value of the $\mathrm{pH}$ increases. ${ }^{13 b, 14 d, 20 a, b}$ Thus, we expected that the deposition of reduced silver atoms onto the surface of the GNRs occurs at high $\mathrm{pH}$. To test our hypothesis, we conducted the following reactions in $200 \mathrm{mM}$ glycine buffers ( $\mathrm{pH}>7.0)$. The GNR seeds were prepared using a seeding method according to a liter ature procedure; ${ }^{140}$ they were used directly without any further purification. Four aliquots of as-prepared GNR solutions $(\mathrm{pH} 3.0 ; 0.5$ $\mathrm{mL}$ ) containing $0.097 \mathrm{mM}$ silver ions and $0.53 \mathrm{mM}$ ascorbic acid were mixed separately with $500 \mathrm{mM}$ glycine buffers $(\mathrm{pH} 7.0,8.0,9.0$, and 10.0; $0.4 \mathrm{~mL}$ ); these mixtures were diluted with water to give final volumes of $2.0 \mathrm{~mL}$. The solutions were then incubated at room temperature for up to $6 \mathrm{~h}$. During the course of the reaction, the color of thesolution at pH 7.0 (rose) remained the same while the other three solutions changed to different degrees of

(16) Gao, J .; Bender, C. M.; Murphy, C.J . Langmuir 2003, 19, 90659070.

(17) J ana, N. R.; Gearheart, L.; Murphy, C.J .J . Phys. Chem. B 2001, 105, 4065-4067.

(18) Henglein, A. J . Phys. Chem. B 2000, 104, 2201-2203.

(19) Hodak, J. H.; Henglein, A.; Hartland, G. V. J . Phys. Chem. B 2000, 104, 5053-5055.

(20) (a) Pal, T.; De, S.; J ana, N. R.; Pradhan, N.; Mandal, R.; Pal, A.; Beezer, A. E.; Mitchell,J . C. Langmuir 1998, 14, 4724-4730. (b) Hodak, J. H.; Henglein, A.; Giersig, M.; Hartland, G. V.J . Phys. Chem. B 2000, 104, 11708-11718. (c) Liu, M.; Guyot-Sionnest, P. J . Phys. Chem. B 2004, 108, 5882-5888. 


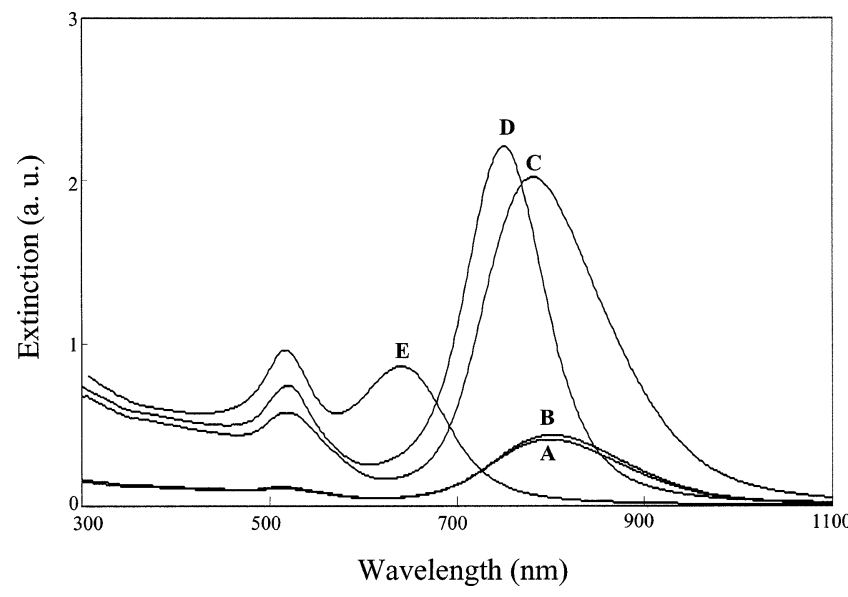

Figure 1. Surfaceplasmon absorption spectra for (A), theinitial GNRs at pH 3.0, and for the GNR in $100 \mathrm{mM}$ glycine solutions containing $0.097 \mathrm{mM}$ silver ions and $0.53 \mathrm{mM}$ ascorbic acid at (B) $\mathrm{pH} 7.0,(\mathrm{C}) \mathrm{pH}$ 8.0, (D) $\mathrm{pH} 9.0$, and (E) $\mathrm{pH}$ 10.0.

magenta. I n comparison, the col or of the solutions did not change in the absence of ascorbate ions. We note that we did not observe AgCl precipitates since silver ions form complexes with glycine. Thus, the solutions were used for UV-vis absorption measurements. For transmission electron microscopy (TEM) measurements, the solutions were subject to centrifugation (12000 rpm for $30 \mathrm{~min}$ ) to remove excess amounts of CTAB.

AsFigure 1 indicates, the UV-vis spectra of thesolution at $\mathrm{pH} 7.0$ and the original GNR solution are similar, whereas the longitudinal plasmon absorption bands of the other three solutions undergo blue shifts. The magnitude of the blue shift increases with increasing values of $\mathrm{pH}$ in the range from 8.0 to 10.0 , which suggests the formation of differently shaped products. Our hypothesis is further confirmed by the TEM images depicted in $\mathrm{F}$ igure 2A-D. TheTEM intensity contrast suggests theformation of Au-Ag core-shell NRs, in which the bright parts show the distribution of silver. ${ }^{20 b, 21}$ The unique shapes of each set of NRs obtained at diffent values of $\mathrm{pH}$ highlight the usefulness of this method for preparing high-quality AuAg core-shell NRs. The formation of the Au-Ag coreshell NRs occurs as the result of the deposition of silver onto the surface of the GNRs once the silver ions are reduced by ascorbate; this situation is confirmed by inductively coupled plasma mass spectrometry, which indicates that the ${ }^{109} \mathrm{Ag} /{ }^{197} \mathrm{Au}$ ratios are $0.046,0.085$, and 0.097 (RSD <2.9\%) at $\mathrm{pH} 8.0,9.0$, and 10.0, respectively, from threeconsecutivemeasurements (20 data points were obtained in each measurement). ${ }^{22}$ The ratios of $\mathrm{Ag}$ to $\mathrm{Au}$ are in good agreement with those obtained by energydispersive X-ray (EDX) spectrometry (three consecutive measurements). A representative EDX spectrum is depicted in Figure 2E. The deposition of silver on GNRs explains why the values of theabsor bance of thesolutions at $\mathrm{pH} 9.0$ and 10.0 (Figure 1 ) are much greater than that of the original solution. It has been known that the Iongitudinal plasmon absorption of GNRs shifts blueand is enhanced with silver coating, mainly because of the changes in diel ectric function and overall aspect ratio, as well as the formation of the Au-Ag interface. ${ }^{20 b, 20 c, 23} \mathrm{We}$ note that the Au-Ag core-shell NRs comprise $>90 \%$ of the nanorods. At $\mathrm{pH}$ 9.0, most of the $\mathrm{Au}-\mathrm{Ag}$ core-shell NRs possess dumbbell-shaped morphologies. The formation of the differently dumbbell-shaped Au-Ag core-shell NRs suggests that the $\{111\}$ facet of the GNRs is more accessibletosilver atoms than is the $\{110\}$ facet, in which densely packed CTAB assemblies were formed. ${ }^{14 b, 24}$ We stress that our results are different from those described for the regular rodlike shapes obtained when using $\mathrm{NH}_{2}-$ $\mathrm{OH}$ to reduce silver on the surface of the GNRs in the absence of CTAB. ${ }^{23}$ Table 1 summarizes the sizes, shapes, and surface plasmon absorptions of theas-prepared GNRs and the Au-Ag core-shell NRs; Chart 1 provides definitions of the descriptors $L_{1}, L_{2}, D_{1}$, and $D_{2}$. Both the length
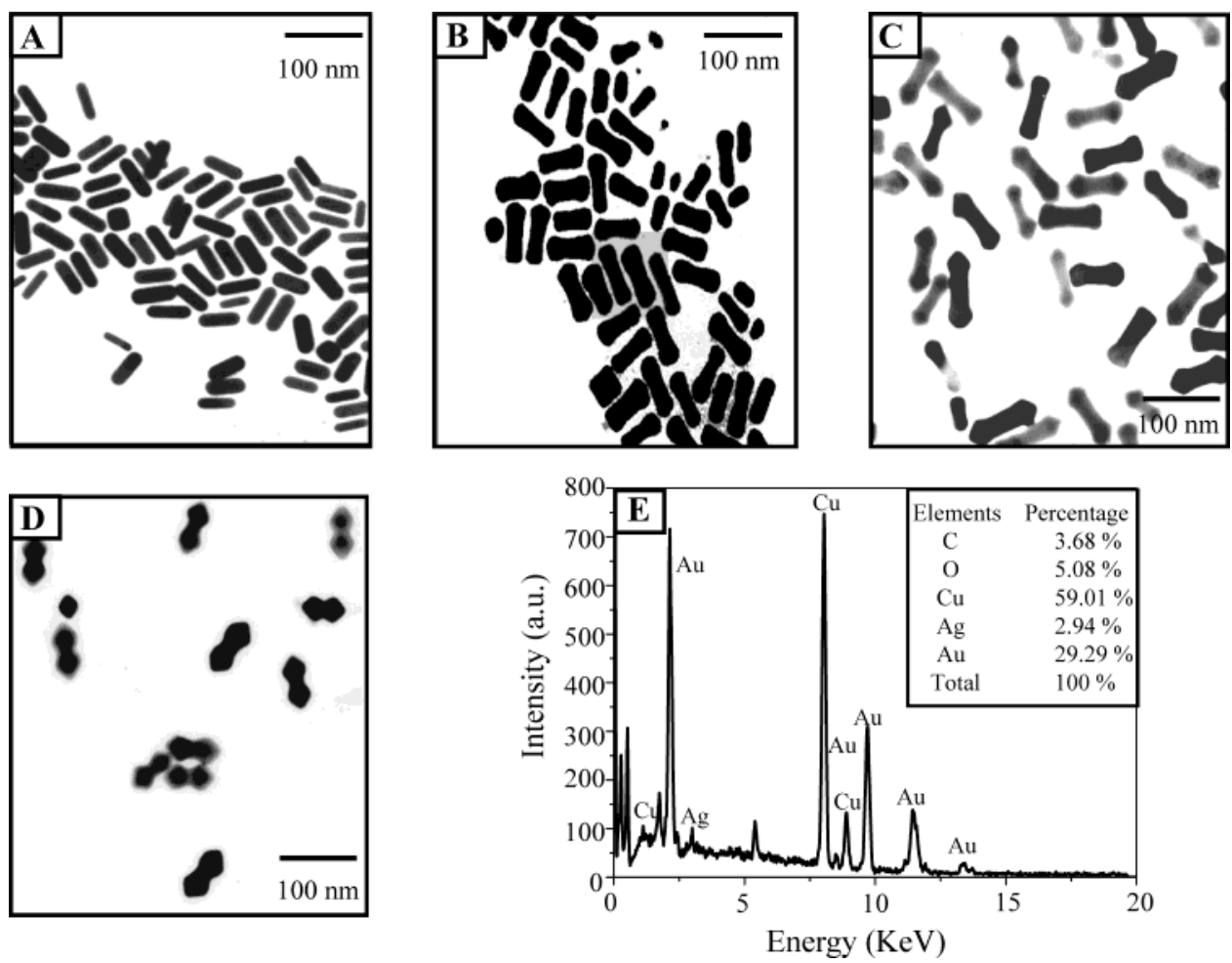

Figure 2. TEM images of the GNR solutions obtained at different values of $\mathrm{pH}$ : (A) $\mathrm{pH} 3.0,(B) \mathrm{pH} 8.0,(\mathrm{C}) \mathrm{pH} 9.0$, and (D) $\mathrm{pH}$ 10.0. A representative EDX spectrum of the GNR at $\mathrm{pH} 10.0$ is depicted in (E). Scale bar $=100 \mathrm{~nm}$. Other conditions are identical to those described in Figure 1. 
Table 1. The Physical and Optical Properties of the GNRs and Au-Ag Core-Shell NRs ${ }^{\mathrm{a}}$

\begin{tabular}{lcccccccc}
\hline & $\mathrm{L}_{1}$ & $\mathrm{~L}_{2}$ & $\mathrm{D}_{1}$ & $\mathrm{D}_{2}$ & $\mathrm{~L}_{1} / \mathrm{D}_{1}$ & $\mathrm{~L}_{1} / \mathrm{D}_{2}$ & $\lambda_{\mathrm{T}}(\mathrm{nm})$ & $\lambda_{\mathrm{L}}(\mathrm{nm})$ \\
\hline GNRs & $53 \pm 4$ & $43 \pm 4$ & $14 \pm 3$ & $14 \pm 3$ & 3.8 & 3.8 & 518 & 797 \\
Au-Ag (pH 8.0) & $56 \pm 8$ & $40 \pm 8$ & $15 \pm 3$ & $16 \pm 4$ & 3.7 & 3.5 & 517 & 781 \\
Au-Ag (pH 9.0) & $65 \pm 8$ & $36 \pm 7$ & $19 \pm 4$ & $24 \pm 4$ & 3.4 & 2.7 & 516 & 750 \\
Au-Ag (pH 10.0) & $58 \pm 5$ & $34 \pm 5$ & $19 \pm 3$ & $28 \pm 2$ & 3.1 & 2.1 & 515
\end{tabular}

a The descriptors $L_{1}, L_{2}, D_{1}$, and $D_{2}$ are defined in Scheme 1 . The descriptors $\lambda_{T}$ and $\lambda_{L}$ represent the maximum wavelengths of the transverse and longitudinal plasmon absorbances, respectively.

Chart 1. The Model Structures of GNRs Listed in Table 1: (A) pH 8.0, (B) pH 9.0, and (C) pH 10.0

A

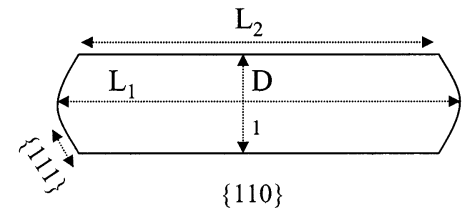

B

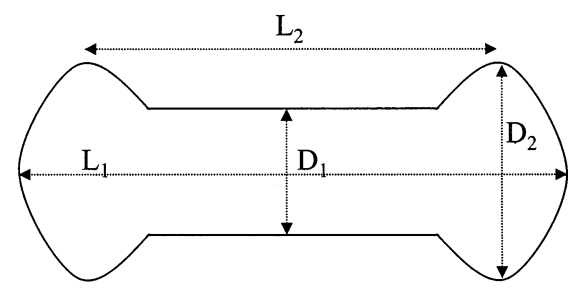

C

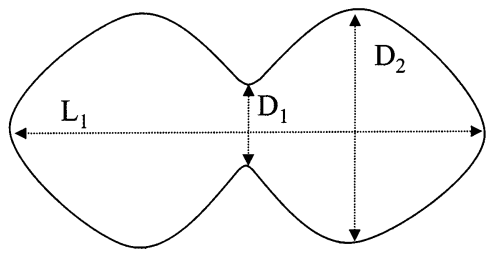

and diameter of the $\mathrm{Au}-\mathrm{Ag}$ core-shell NRs increase, whereas the ratio $L_{1}: D_{2}$ decreases, as greater amounts of silver become deposited onto the surface of the GNRs at increasing values of $\mathrm{pH}$. Since the $\mathrm{L}_{1}: \mathrm{D}_{2}$ ratio is similar to the aspect ratio, we expected that the Iongitudinal plasmon absorbance bands would shift toward the blue and thetransverse absorption would shift toward the red upon increasing thepH. ${ }^{19,25}$ Surprisingly, we observeonly the blue shift in the longitudinal plasmon absorption bands, but not a shift in the transverse plasmon absorbance bands, mainly because of the contribution of the absorbance of the $\mathrm{Ag}$ shell. $20 \mathrm{~b}, 24$ It is also important to notethat the $\mathrm{Au}-\mathrm{Ag}$ core-shell NRs prepared at both $\mathrm{pH}$ 8.0 and 9.0 display approximately 5 -fold enhancements in their longitudinal plasmon absorbance rel ative to that of the GNRs. $20 \mathrm{a}, 20 \mathrm{~b}, 23$ Theintensities of both thetransverse and longitudinal plasmon absorption bands are further enhanced as the concentration of $\mathrm{AgNO}_{3}$ is increased. ${ }^{20 b, 23}$ The longitudinal surface plasmon absorbance shifts to shorter wavelengths upon increasing the concentration of silver ions, which indicates that thesilver shell is thicker at higher concentrations of silver ions. ${ }^{20 b, 20 c, 23} \mathrm{~A}$ new absorption band appears at ca. $408 \mathrm{~nm}$ in the cases where $\mathrm{AgNO}_{3}$ was used at concentrations $>0.50 \mathrm{mM}$, which is due mainly to the formation of silver NPs; this situation is supported by the TEM image (not shown).

Figure 3 depicts theevolution with time of theformation of the differently dumbbell-shaped Au-Ag core-shell NRs. The rates of formation of the $\mathrm{Au}-\mathrm{Ag}$ core-shell NRs at $\mathrm{pH} 8.0$ and 9.0 slowed after 100 and $25 \mathrm{~min}$, respectively. Weattribute the faster rate that occurs at $\mathrm{pH} 9$ to be due mainly to the increased concentration of ascorbate ions,
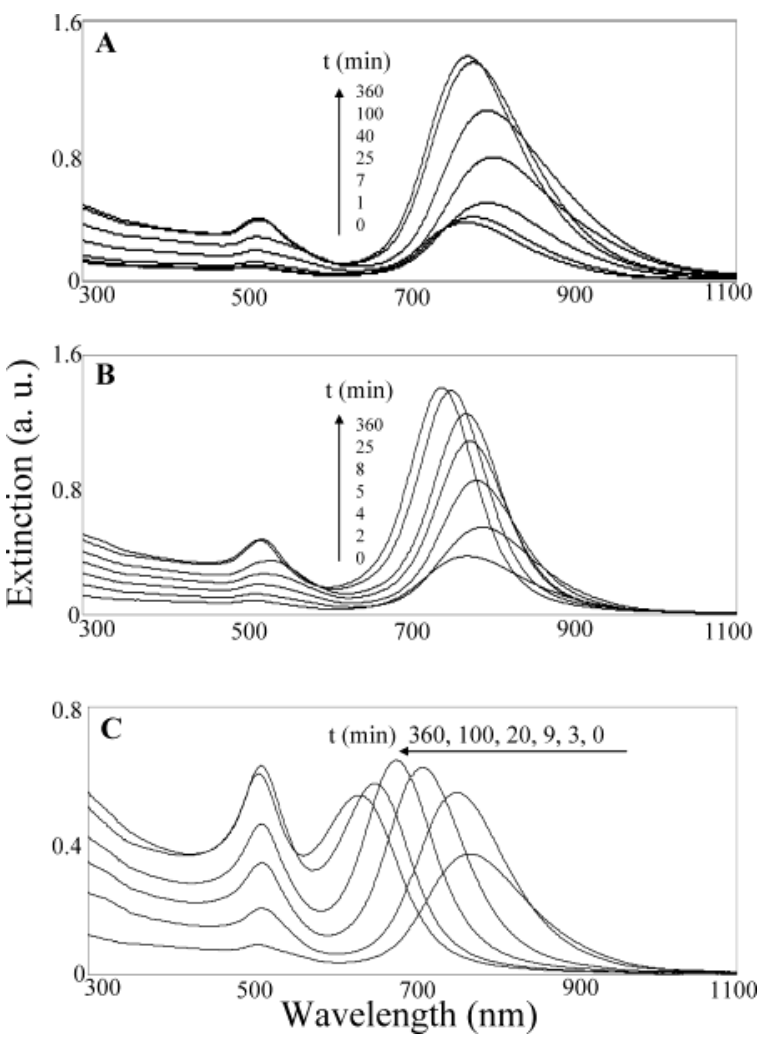

Figure 3. UV-vis absorption spectra displaying the time evolution of the formation of the $\mathrm{Au}-\mathrm{Ag}$ core-shell NRs: (A) $\mathrm{pH}$ 8.0, (B) $\mathrm{pH} 9.0$, and (C) $\mathrm{pH}$ 10.0. Other conditions identical to those described in Figure 1.

which possess greater reducing ability than does ascorbic acid. At pH 10.0, the longitudinal plasmon absorbance band undergoes a gradual blue shift and the transverse plasmon absorbancegradually increases during thecourse of the reaction (360 $\mathrm{min}$ ). We believe that the longer reaction time needed at $\mathrm{pH} 10.0$ is likely to be due to the slower rate of deposition as the Ag shell becomes thicker. Theas-prepared dumbbell-shaped GNRs all arestablein glycine buffers $(\mathrm{pH} 3.0-10.0)$ for at least 3 months, indicating that glycine likely coated on their surface.

In summary, we describe an easy and reproducible method for preparing high-quality dumbbell-shaped bimetallic $\mathrm{Au}-\mathrm{Ag}$ core-shell NRs. Silver ions are reduced effectively by ascorbate ions under alkaline conditions and become coated subsequently onto the surfaces of the GNRs. Becausethecoating of silver occurs anisotropically

(21) Srnova-Sloufova, I.; Lednicky, F .; Gemperle, A.; Gemperlova, J Langmuir 2000, 16, 9928-9935.

(22) Wrobel, K.; Sadi, B. B. M.; Wrobel, K.; Castillo, J . R.; Caruso, J . A. Anal. Chem. 2003, 75, 761-767.

(23) Ah, C. S.; Hong, S. D.; J ang, D.-J . J . Phys. Chem. B 2001, 105, $7871-7873$.

(24) Wang, Z. L.; Gao, R. P.; Nikoobakht, B.; El-Sayed, M. A.J . Phys. Chem. B 2000, 104, 5417-5420. 8426 
on the surface of the GNRs in the presence of CTAB, the morphology of the Au-Ag core-shell NRs produced depends on the value of $\mathrm{pH}$ and on the concentration of $\mathrm{AgNO}_{3}$. From our preliminary results, we note that this simple method may be extended to the synthesis of different $\mathrm{Au}$-metal core-shell NRs merely by controlling the value of the $\mathrm{pH}$ and the nature and concentration of the buffer soluti on and reducing agents. I t is worth noting that the Au-Ag core-shell NRs described herein possess stronger plasmon absorptions than do GNRs and, thus, they have great potential for many applications, such as the detection of biomolecules and ions. 6,26,27

Acknowledgment. This work was supported by the National ScienceCouncil (NSC 93-2120-M-002-001) of the Republic of China.

\section{LA048791W}

(26) Hirsch, L. R.; J ackson, J . B.; Lee, A.; Halas, N. J .; West, J . L. Anal. Chem. 2003, 75, 2377-2381.

(27) Lee, T. M.-H.; Li, L.-L.; Hsing, I.-M. Langmuir 2003, 19, 4338 